\title{
Preparation of ionic liquid-immobilized expanded perlite and its analytical application
}

\author{
Jie Liu Almojtaba Bakheet Xiashi Zhu* \\ College of Chemistry \& Chemical Engineering, Yangzhou University, Yangzhou 225009, China \\ *Corresponding Author: xszhu@yzu.edu.cn
}

\begin{abstract}
The ultra-light weight ionic liquid immobilized expanded perlite (IL-EP) was synthesized and characterized by Fourier transform infrared (FTIR) spectroscopy and scanning electron microscopy (SEM). ionic liquid immobilized expanded perlite (IL-EP) as a novel adsorbent solid phase extraction (SPE) coupled with UV-visible absorption spectrometry for the determination of abiraterone acetate/abiraterone was established. The results were shown that the IL-EP could be conveniently separated The method was applied to analyzing abiraterone acetate/ abiraterone in tablet and serum samples with reasonable results.
\end{abstract}

Keywords: Abiraterone acetate; abiraterone; ionic liquid modified expanded perlite;

\section{Introduction}

Expanded perlite (EP) is inexpensive and abundantly available, most of perlite contains greater than $70 \%$ silica and are adsorptive [1], which could make it an economical adsorbent for removing heavy metals [2] and organic matter [3]. Moreover, EP was classified as ultra-light weight material with a density of about $32 \mathrm{~g} / \mathrm{L}$, which is also an excellent candidate in solid phase extraction. Its characteristic was that it could float on the surface of the water and conveniently separated without centrifugation. In this study, ultra-light weight ionic liquid immobilized expanded perlite (IL-EP) was synthesized and characterized by Fourier transform infrared (FTIR) spectroscopy and scanning electron microscopy (SEM). The IL-EP-solid phase extraction followed by UV-Vis was applied to separation/analysis abiraterone acetate/abiraterone in real samples.

\section{Experimental}

\subsection{Apparatus and reagents}

Bruker Tensor 27 spectrometer (Bruker Company, Germany); SEM Hitachi S-4800 II; UV-2500 spectrophotometer (Shimadzu Corporation, Japan);A centrifuge (Anke Scientific Instrument Factory, Shanghai).

All chemicals and reagents were at least of analytical reagent grade, unless otherwise stated.

\subsection{Synthesis of $\left.\left[\mathrm{C}_{8} \mathrm{MIM}\right]\left[\mathrm{PF}_{6}\right]\right)$ immobilized expanded perlite}

The $\left[\mathrm{C}_{8} \mathrm{MIM}\right]\left[\mathrm{PF}_{6}\right]$ was synthesized as reported in a previous literature [4].

To immobilize the $\left[\mathrm{C}_{8} \mathrm{MIM}\right]\left[\mathrm{PF}_{6}\right]$ on the surface of the expanded perlite, 0.50 grams of EP (pretreatment at $110{ }^{\circ} \mathrm{C}$ for $1 \mathrm{~h}$ ) was immersed into acetone solution containing 2.00 $\mathrm{g}\left[\mathrm{C}_{8} \mathrm{MIM}\right]\left[\mathrm{PF}_{6}\right]$. After vortex-mixed for $2.5 \mathrm{~h}$, the mixture were shaked into $50 \mathrm{~mL}$ redistilled water to wipe off redundant ionic liquid. Then volatile components in the mixture were removed on a drying oven. Then the resulting solution dried in air at $60{ }^{\circ} \mathrm{C}$, leading to IL-EP.

\subsection{Adsorption and elution of abiraterone acetate or abiraterone}

A $60.0 \mathrm{~mL}$ of the working solution or aqueous sample and $0.10 \mathrm{~g}$ of IL-EP were transferred into a centrifuge tube, and the solution in the tube was subsequently shaken in the constant temperature shaking table for $30 \mathrm{~min}$ at room temperature. Then, IL-EP with adsorbed target was separated from the solution by filtration. The residual analyte in the supernatants was determined by UV-vis at $246 \mathrm{~nm}$. 
Adsorption of abiraterone acetate or abiraterone IL-EP with $4.0 \mathrm{~mL}$ ethanol shaking elution $60 \mathrm{~min}$, eluent were determined by the UV-vis.

\section{Results and discussion}

\subsection{Preparation and characterization of IL-EP}

\subsubsection{Characterization by FTIR}

FTIR spectra of EP and IL-EP were shown in Fig.1. (1) Curve A was the spectra of EP, the strong peaks of $1100-1000 \mathrm{~cm}^{-1}$ correspond to the Si-O-H and Si-O-Si stretching vibration; And the peak of the absorption peak of $\mathrm{Si}-\mathrm{O}-\mathrm{H}$ on the surface of EP at $3639 \mathrm{~cm}^{-1}$. (2) Both characteristic peaks of EP and IL $\left(\sigma_{\mathrm{Si}-\mathrm{O}-\mathrm{Si}}=1100-1000 \mathrm{~cm}^{-1}\right.$, $\sigma_{\text {Si-O-H }}=3639 \mathrm{~cm}^{-1}, \sigma_{\mathrm{C}=\mathrm{C}}=1573-1466 \mathrm{~cm}^{-1}, \sigma_{\mathrm{P}-\mathrm{F}}=840 \mathrm{~cm}^{-1}$ ) were appeared in curve $B$. So the $\left[\mathrm{C}_{8} \mathrm{MIM}\right]\left[\mathrm{PF}_{6}\right]$ was successfully immobilized on EP.

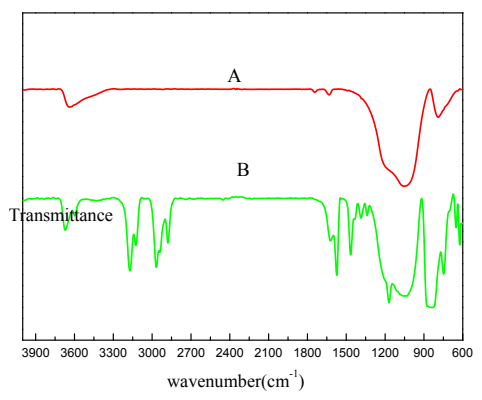

Fig.1. Infrared spectra of (A) EP (B) IL-EP

\subsubsection{Characterization by SEM}

The morphological structures of IL and IL-EP were investigated with the scanning electron micrographics. The EP had a rough surface and cellular structure from Fig.2.A. Compared with EP, the morphology of IL-EP (Fig.2B) was distinctly different, which revealed the presence of ionic liquid. Therefore, together with the results of FTIR, the $\left[\mathrm{C}_{8} \mathrm{MIM}\right]\left[\mathrm{PF}_{6}\right]$ was successfully immobilized on EP.

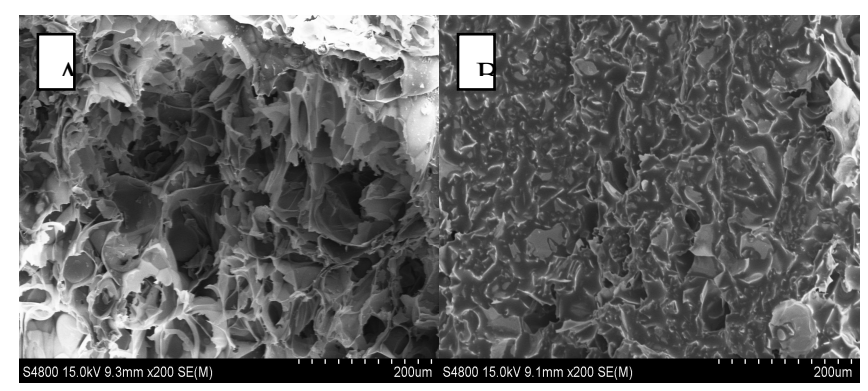

Fig.2. SEM image (A) EP (B) IL-EP

\subsection{Optimization of adsorption}

The factors affecting the adsorption process of abiraterone acetate/abiraterone such as $\mathrm{pH}$, temperature, sample volume and adsorption time were discussed.

\subsubsection{Effect of $\mathrm{pH}$}

The effect of $\mathrm{pH}$ was examined in the $\mathrm{pH}$ range of 2.013.0 (Fig. 3).The results depicted that (1) the adsorption behavior of abiraterone acetate on IL-EP was similar to abiraterone and the adsorption efficiency could remain above $85 \%$ (curve.1, 2 ); (2) both of them could not quantitatively absorbed on IL-EP (curve.3 and 4 ). These results indicated that the adsorption ability of IL-EP for analytes was greatly improved. Consequently, all extractions were executed in natural medium by IL-EP.

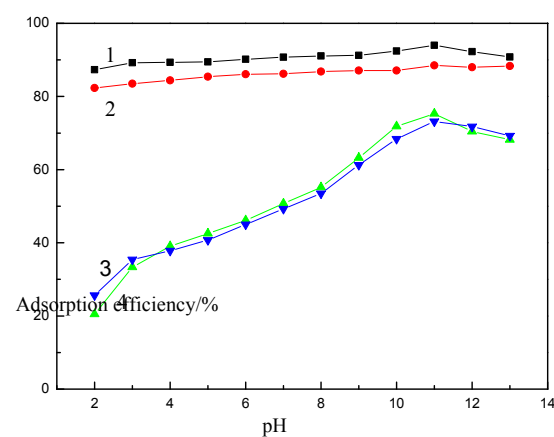

Fig.3. Effect of $\mathrm{pH}$ on adsorption efficiency

1. abiraterone acetate-IL-EP 2. abiraterone-IL-EP

3. abiraterone acetate-EP 4. abiraterone-EP

\subsubsection{Effect of adsorption temperature and time}

The adsorption of the analyte was conveniently carried out at room temperature and 30 min of extraction time was performed for further study.

\subsubsection{Effect of sample volume}

The concentration of abiraterone acetate/abiraterone was fixed at $8.0 \mu \mathrm{g} \mathrm{mL} \mathrm{m}^{-1}$, and the volume of the sample solution was increased from 5.0 to $70.0 \mathrm{~mL}$. It could be seen in Fig.8, the adsorption efficiency was greater than $85 \%$ in the sample volume of $5.0-60.0 \mathrm{~mL}$, and decreased when the sample volume was greater than $60.0 \mathrm{~mL}$, so the allowed sample volume was $60.0 \mathrm{~mL}$.

\subsection{Adsorption capacity}

Adsorption capacity, defined as the maximum amount of analyte adsorbed per gram of IL-EP. The adsorption capacity of IL-EP for abiraterone acetate abiraterone was $3.63,3.25 \mathrm{mg} \mathrm{g}^{-1}$, respectively. 


\subsection{Optimization of elution}

\subsubsection{Selection of eluent}

The selection of eluent type is of vital importance which determines the final extraction efficiency. Therefore, several eluent $(\mathrm{NaOH}, \mathrm{HCl}, \mathrm{SDS}, \mathrm{ACN}$, carbinal, ethanol) were tested in this work. As could be seen from Fig. 4, the ethanol had the strongest elution capacity for abiraterone acetate/abiraterone. Thus, ethanol was chosen as final eluent.

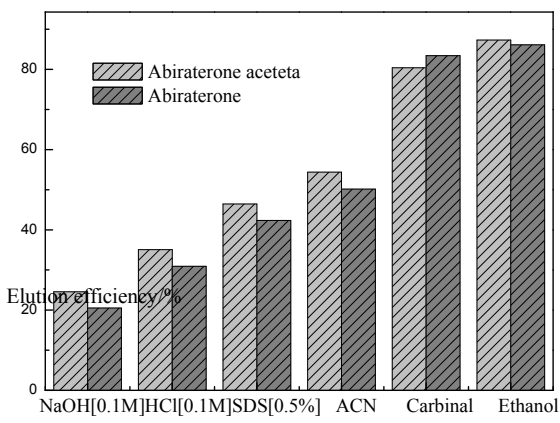

Fig.4. Effect of different dissolvent on elution efficiency

3.4.2. Effect of elution temperature, time and eluent volume

The elution was performed at room temperature. 60 min of elution time and the optimum volume of ethanol solution chosen for this work was $4.0 \mathrm{~mL}$.

\subsection{Reuse of IL-EP}

The reusability of IL-EP was evaluated through consecutive adsorption and elution cycles. The IL-EP material could be reused at least 10 times along with the adsorption efficiency of above $83 \%$ for abiraterone acetate and abiraterone .

\subsection{Effect of interference}

With a relative error less than $\pm 5 \%$, the influence of some interferents in samples on the determination of abiraterone acetate and abiraterone was studied and the tolerance limit is shown as follows (Table 1). The results indicated that the majority of these substances in samples had no remarkable interference on the determination of abiraterone acetate/abiraterone.

Table. 1 Tolerance limits of interfering substances

Tested substances Tolerance ratio

\begin{tabular}{cc}
\hline Glucose & 1000 \\
$\mathrm{SO}_{4}^{2-}, \mathrm{Cl}^{-}$ & 500 \\
$\mathrm{Na}^{+}, \mathrm{K}^{+}$ & 500 \\
Lactose & 500 \\
$\mathrm{Zn}^{2+}, \mathrm{Mg}^{2+}, \mathrm{Ca}^{2+}{ }^{+} \mathrm{Ni}^{2+}$, & 500 \\
$\mathrm{~Pb}^{2+}$ & \\
$\mathrm{Tartaric}^{2} \mathrm{acid}$ & 125 \\
$\mathrm{Cu}^{2+}$ & 50 \\
\hline
\end{tabular}

\subsection{Analytical performance of the method}

Under the optimum conditions, the analytical figures of this method were evaluated and summarized in Table 2.

Table.2. The performance characteristic of this method

\begin{tabular}{ccc}
\hline Parameters & $\begin{array}{c}\text { Abiraterone } \\
\text { acetate }\end{array}$ & Abiraterone \\
\hline linear equation $(\mu \mathrm{g} / \mathrm{mL})$ & $\mathrm{A}=0.0640 \mathrm{c}+0.0456$ & $\mathrm{~A}=0.0610 \mathrm{c}+0.0412$ \\
\hline Correlation $(\mathrm{r})$ & 0.9989 & 0.9973 \\
Linear range $(\mu \mathrm{g} / \mathrm{mL})$ & $0.01-30.00$ & $0.07-32.00$ \\
L.O.D. $(\mathrm{ng} / \mathrm{mL})$ & 3.00 & 5.00 \\
R.S.D. $(\mathrm{n}=3, \mathrm{c}=8.00$ & & $1.51 \%$ \\
$\mu \mathrm{g} / \mathrm{mL})$ & $1.42 \%$ & \\
\hline
\end{tabular}

\subsection{Analytical application}

The method was applied to determine abiraterone acetate in abiraterone acetate tablets, recovery experiments about abiraterone acetate/abiraterone in human serum

The result of abiraterone acetate tablet obtained by the proposed method was in good agreement with the HPLC(table 3$)$. The statistical $t$-test $(\mathrm{P}=0.95)$ was used to compare the results from both methods, which showed that there was no significant difference between them.

Table.3 Results of abiraterone acetate determination in tablet $(\mathrm{n}=3)$

\begin{tabular}{ccc}
\hline Sample & $\begin{array}{c}\text { Proposed method } \\
(\mathrm{mg} / \text { tablet })\end{array}$ & $\begin{array}{c}\text { HPLC method } \\
(\mathrm{mg} / \text { tablet })\end{array}$ \\
\hline $\begin{array}{c}\text { abiraterone acetate } \\
\text { tablet }\end{array}$ & 123.8 & 125.0 \\
\hline
\end{tabular}

A recovery study was also performed using standard 
addition method with the analytes at three different concentrations (5.00, 10.00 and $15.00 \mu \mathrm{g} \mathrm{mL}^{-1}$ ). The data, which summarized in Table 4 , showed desirable recovery values in all instances and the proposed methodology was suitable for determination of abiraterone acetate and abiraterone in human serum.

Table. 4 The recoveries of abiraterone acetate and abiraterone in human serum.

\begin{tabular}{cccccc}
\hline & & \multicolumn{3}{c}{ Found $(\mu \mathrm{g} / \mathrm{mL})$} & \multicolumn{2}{c}{$\begin{array}{c}\text { Recovery }(\%) \\
(\mathrm{n}=3)\end{array}$} \\
Sample & $\begin{array}{c}\text { Added } \\
(\mu \mathrm{g} / \mathrm{mL})\end{array}$ & $\mathrm{AC}^{1}$ & $\mathrm{~A}^{2}$ & $\mathrm{AC}$ & $\mathrm{A}$ \\
\hline \multirow{2}{*}{ Human } & 0.00 & $\mathrm{ND}$ & $\mathrm{ND}$ & - & - \\
serum & 10.00 & 9.90 & 9.97 & 99.0 & 99.7 \\
& 15.00 & 15.30 & 14.91 & 102.0 & 99.4 \\
\hline
\end{tabular}

AC:Abiraterone acetate;A:Abiraterone

\section{Conclusion}

In this research, IL-EP was synthesized and its adsorptive features were investigated for abiraterone acetate /abiraterone. IL-EP did have better absorption capacity, cost-effective, ease of synthesis and separated. The proposed method for the analysis of abiraterone acetate and abiraterone in real sample were satisfactory.

\section{Acknowledgment}

The authors acknowledge the financial support from the National Natural Science Foundation of China(21375117) and and a project funded by the Priority Academic Program Development of Jiangsu Higher Education Institutions.

\section{References}

(1)M.Alkan, M.Dogan, Adsorption of copper (II) onto perlite, Journal of Colloid and Interface Science, 243:280-291.2001

(2)A.Sar, M.Tuzen, D.Ctak, M.Soylak, Adsorption characteristics of $\mathrm{Cu}(\mathrm{II})$ and $\mathrm{Pb}(\mathrm{II})$ onto expanded perlite from aqueous solution, Journal of Hazardous Materials, 148:387-394,2007

(3)D.Mehmet, A.Mahir. Removal of methyl violet from aqueous solution by perlite, Journal of Colloid and
Interface Science,267:32-41.2003

(4)F.Y. Zhao, J.Y.Wang, H.J.Liu, R.J.Liu. Synthesis and properties of a series of room-temperature ionic liquids $\mathrm{N}$-alky-l-N-methyimidazolium hexafluorophosphates, Huaxue Shiji,4(29):229-231.2007 